\title{
Performance Assessment of Japanese Electricity and Gas Companies during 2002-2018: Three DEA Approaches
}

\author{
Toshiyuki Sueyoshi ${ }^{1,2}$ and Mika Goto ${ }^{3, *}$ \\ 1 Department of Management, New Mexico Institute of Mining \& Technology, 801 Leroy Place, \\ Socorro, NM 87801, USA; toshiyuki.sueyoshi@nmt.edu \\ 2 Tokyo Tech World Research Hub Initiative, Tokyo Institute of Technology, School of Environment and Society, \\ 3-3-6, Shibaura, Minato-ku, Tokyo 108-0023, Japan \\ 3 Tokyo Institute of Technology, School of Environment and Society, 3-3-6, Shibaura, Minato-ku, \\ Tokyo 108-0023, Japan \\ * Correspondence: goto.m.af@m.titech.ac.jp
}

Citation: Sueyoshi, T.; Goto, M.

Performance Assessment of Japanese Electricity and Gas Companies during 2002-2018: Three DEA Approaches. Energies 2021, 14, 1705. https://doi.org/10.3390/en14061705

Academic Editor: Vincenzo Bianco

Received: 11 February 2021

Accepted: 15 March 2021

Published: 18 March 2021

Publisher's Note: MDPI stays neutral with regard to jurisdictional claims in published maps and institutional affiliations.

Copyright: (c) 2021 by the authors. Licensee MDPI, Basel, Switzerland. This article is an open access article distributed under the terms and conditions of the Creative Commons Attribution (CC BY) license (https:// creativecommons.org/licenses/by/ $4.0 /)$.

\begin{abstract}
This study has compared Japan's major electricity and gas companies in terms of their corporate performance measures from 2002 to 2018 using three types of Data Envelopment Analysis (DEA) approaches. We develop a new type of efficiency measures and indexes for DEA and then compare the performance of major electric power companies and city gas companies by examining a recent data set that include years after the Fukushima Daiichi Nuclear Power Plant accident. The data set incorporates the number of patents as an output that represents companies' capability for technology innovation to investigate intertemporal changes of efficiency through index measures. The results provide us with two important findings. First, the electricity industry has experienced long-term difficulty due to the nuclear plant disaster; while the gas industry experienced less difficulty from the accident. Second, both industries have been gradually improving performance measures in recent years. However, the gas industry has outperformed the electricity industry. From the results, this study discusses important policy implications for Japan's energy utility industry and academic research on the industry.
\end{abstract}

Keywords: efficiency assessment; electricity; gas; synergy effect; data envelopment analysis

\section{Introduction}

Electricity and gas supply companies are classified into the utility sector that provides public services for people, including water, sewage, electricity, and gas. Traditionally, these utility companies were investor-owned companies regulated by governments or, in some cases, state-owned entities, because of the public nature of their services.

Since the 1990s, liberalization and deregulation of electricity and gas supply industries started in many nations. Nations have been following the famous, early example of deregulation and privatization of electricity and gas by a market reform conducted under the Thatcher administration in the United Kingdom started in the 1980s [1]. Many European and other nations followed the trend of electricity and gas market liberalization [2]. Such a change in energy markets created opportunities for electricity and gas companies to enter each other's markets by acquiring firms. Energy mergers changed corporate strategies to accept new market competition. Previous studies $[3,4]$ provide detailed descriptions on mergers in Europe and the United States.

In line with the global trend, Japan gradually liberalized electricity and gas markets beginning in 1995. The nation first introduced partial competition into the electricity generation market, starting with competitive bidding for new generation capacities. Retail competition began in the gas supply service for large consumers, followed by retail market liberalization of electricity and gas [5]. 
Japanese utility services have two unique features that are not found in other industrial countries such as the United States and European nations. First, after a series of market reforms, Japan did not experience significant changes in both electricity and gas markets until the Great East Japan Earthquake (GEJE) and the subsequent disaster at the Fukushima Daiichi Nuclear Power Plant on 11 March 2011. After the huge disaster, electricity and gas market reforms gained momentum, and the Japanese government started to implement drastic reforms. The second unique feature is that, although electricity and gas companies have experienced different market reforms, they have predominantly progressed in a parallel framework for retail market liberalization, because the two industries belong to energy utility services. Both have large social infrastructures under similar government regulation. In addition, the Japanese government, specifically the Agency for Natural Resources and Energy (ANRE) under the Ministry of Economy, Trade, and Industry (MEIT), expects that integrated electricity and gas energy companies will support resilient domestic energy supply, and enter foreign energy markets by fully utilizing scale benefits, efficient operations, and technological capabilities [6,7]. Therefore, assessment of corporate efficiency of energy companies provides fundamental information for corporate managers and policy makers to realize the future plan.

The purpose of this study is to compare Japanese electricity and gas firms using the new type of DEA performance measures (i.e., efficiencies and indexes). The nuclear disaster at Fukushima in 2011 produced economic damages on the national economy and changed electricity and gas market reforms. We examine the influence on these measures to discuss implications for corporate management of energy companies. To attain the aim, this study uses Data Envelopment Analysis (DEA) to measure and compare performances of two groups of utility firms. The DEA approach avoids the specification of a functional form that describes relationship among production factors. It belongs to a non-parametric approach to calculate efficiency measures of various organizations. However, the DEA does not have statistical inference; therefore, we cannot conduct statistical tests at the level of econometrics. This study discusses a new type of DEA assessment concerning a performance change over time and then describes non-parametric statistical tests applicable to DEA-based performance measures. As discussed in [8], which provides a detailed survey on previous DEA studies applied to energy and environment, DEA has been a practical and effective tool for performance assessment for energy companies.

The structure of this research is organized as follows: Section 2 summarizes a literature review related to this study and specifies the position of this research. Section 3 describes methodological features of the newly proposed DEA approach. Section 4 documents our empirical results. Section 5 summarizes this study along with future research tasks. Finally, this article lists Abbreviations and Nomenclature.

\section{Literature Review}

An economic assertion long believed by many researchers (e.g., [9]) is that "there are similarities between electricity and gas services in the utility industry. They have a synergy effect between them." Studies $[10,11]$ have empirically investigated the assertion by comparing electricity specialized and diversified firms in the United States(US). Using DEA and DEA-DA (Discriminant Analysis) as methodological tools, they concluded that the two utility services did not have technological similarities at the level that gas service had received the benefit of a synergy effect with electricity. The core business concentration was more effective for electric firms than corporate diversification under US deregulation.

This study extends previous research efforts [9-11] by changing the region of investigation from the US to Japan. There are two rationales on why Japanese utility firms must be investigated. First, the Japanese electricity industry has been influenced by the 2011 disaster of Fukushima Daiich Nuclear Power Plants. Therefore, it is of interest for not only researchers but also policy makers and utility managers to analyze temporal performance changes and impacts of the accident using the updated data set. Second, the two utility industries have been regulated by the Japanese government, not the US. We expect to find 
new implications on corporate management and industrial policy from operational efficiency assessment under energy market liberalization in Japan, which would be different from previous studies analyzing energy companies in the US. These reasons motivate the research direction of this study.

In addition, with current technology, we may expect business similarities between the two utility services, particularly in a vertically related business structure from upstream to downstream functions. For example, industries have vast networks from production, transportation (i.e., operation of transmission and distribution networks and gas conduit facilities), and retail functions. As discussed by the research [9], there may be a synergy effect in operations toward integrated energy companies in Japan. Thus, we discuss potential synergy effect and implications for corporate strategy from comparative analysis of operational efficiency measures and indexes between electricity and gas companies.

In reviewing previous DEA applications in recent years, there are some studies that examine productivity or operational performance of electric power companies. For example, ref. [12] proposed a dynamic slack-based DEA model to measure the electricity generation sector's efficiency of 24 Latin American and Caribbean countries under consideration of undesirable outputs in the period 2000-2016. Ref. [13] proposed a combination model with DEA and Malmquist index to evaluate the total-factor energy efficiency in thermal power industry. Some other studies measure energy efficiency and environmental sustainability of various entities using DEA. Those studies include [14], which has showed the link between energy efficiency and sustainable economic and financial development in Organization for Economic Co-operation and Development (OECD) countries for the period 2000-2018 by using DEA and regression analysis, and [15], which employed DEA of the slack-based measurement for bad output to assess the transport energy efficiency of 19 countries. The study [16] summarized the latest research on DEA in the field of energy efficiency and discusses the overall situation of related literature published in 2011-2019. The research in [17] examined the environmental sustainability of road transport for a group of OECD countries over the period 2000-2014. However, there was no research that conducts electricity and gas companies' comparative performance assessment using a long-term updated data set, although this study discusses the similarity of business structures and deregulation processes between them from the perspective of synergy effect.

The position of this study is as follows. Examining existing literature and shifting our focus to Japan's energy market, we can indicate that the studies on efficiency of the Japanese power sector have used relatively old data sets. For instance, ref. [18] used data from 1981-1995, and ref. [19] used data from 2004-2008. An exception was [20], which compared the electric power sectors between Japan and South Korea over five years from 2014-2018, but the study did not incorporate gas companies for the efficiency assessment and the study period was relatively short. In addition, efficiency analysis of Japan's city gas companies has not drawn attention from researchers. One reason for the academic gap is that the city gas companies operate in limited metropolitan areas (e.g., Tokyo metropolitan areas) and firm sizes are relatively small, compared to electricity utility companies whose business areas cover the whole of Japan. Thus, there are only two large gas companies (i.e., Tokyo Gas Co., Ltd., Tokyo, Japan and Osaka Gas Co., Ltd., Osaka, Japan) and they are supposed to be vertically unbundled between gas transportation and other functions from production to retailing in 2022, following the vertical separation in electricity companies in 2020. In view of these previous studies, this study attempts to update the performance assessment of electricity and gas companies under the ongoing drastic progress of energy market liberalization in Japan. In this regard, this study seeks to add new empirical values to the existing DEA applications to Japanese utility sectors, along with a methodological contribution to them by proposing new DEA approaches. We consider (a) developing a new type of DEA approaches over time and (b) comparing the performance of major electric power companies and city gas companies, examining a recent data set after gamechanging events (the Fukushima Daiichi Nuclear Power Plant accident) and a series of market reforms. In addition, we incorporate variables that represent technology innovation, 
patents to elucidate intertemporal changes of holistic efficiency by newly proposed index measures of electricity and gas utility companies. The use of such research features indicates the contribution of this study.

\section{Method of Three DEA Approaches}

This study uses three DEA approaches to measure (a) operational efficiency, (b) window analysis for efficiency, and (c) window analysis for index. They provide different analytical implications related to Japanese utility services. Since the window analysis has not been widely used in previous research on energy utilities, we formulate this approach along with a description on differences between efficiency and index measures.

\subsection{Visual Descriptions}

\subsubsection{Differences in Efficiency and Index Measures}

Figure 1 depicts how to determine the degree of efficiency and index measure on the two coordinates $\left(g_{1} / x\right.$ and $\left.g_{2} / x\right)$. For illustration, consider a window with two periods in the figure, and in this case, the window contains two observations (i.e., $C_{t-1}$ in the $t-1$ th period and $C_{t}$ in the $t$ th period). The index measure additionally considers $C_{t+1}$ in the $t+1$ th period. The window shifts to the next adjacent periods (e.g., $t$ and $t+1$ ). The projected point of $C_{t}$ locates $C_{t}^{e}$ on the efficiency frontier of the $t$ th period. This description is also applicable to the case of the previous $(t-1)$ period. Such a case implies that $C_{t-1}$ projects onto $C_{t-1}^{e}$ in Figure 1. The window with the two periods combines the efficiency frontiers of the $t-1$ and $t$ th periods. Therefore, $C_{t-1 \& t}^{e t}$ becomes a projected point of $C_{t}$ on an efficiency frontier to cover the two frontiers.

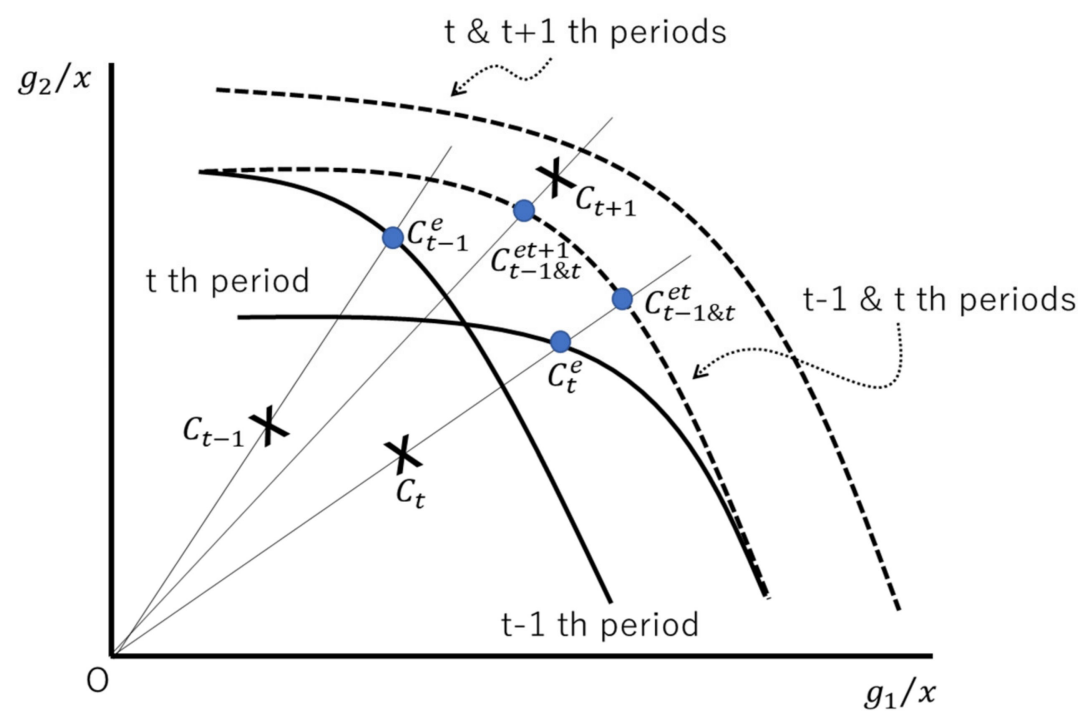

Figure 1. Visual Description of Efficiency and Index Measures (Three Periods). Note: The window analysis prepares a single frontier even if multiple frontiers cross over each other. This is a methodological benefit.

A benefit of the window analysis is that it avoids a difficulty in finding an overlap occurrence between $t-1$ th and th periods (and more periods). The efficiency frontier of the $t-1$ th and the $t$ th covers all observations in the two periods. The frontier can be considered as the best group of efficient performers within the two periods. This type of treatment handles an overlap between multiple periods, for example, in the utility industries. The industry's operations consist of a large-scale production process with matured technology in which we cannot identify fast growing technology innovation, thereby yielding the overlap. Moreover, the corporate value of utility companies is mainly due to stock prices. Hence, their values often fluctuate depending on the strength of the 
economy. Thus, the overlap or retreat among efficiency frontiers may occur in any periods. See [21], which provides a detailed description of DEA window analysis.

The window approach used in this study measures the degree of operational efficiency $(O E)$ of the $k$ th decision-making unit (DMU) based on multiple (e.g., the $t-1 \& t$ th) frontiers. In addition, this study describes how to measure the level of operational index $(O I)$ from the frontier. This is a new type of application of the DEA-window analysis. In Figure 1, we measure $O E$ by $O C_{t} / O C_{t-1 \& t}^{e t}$, so that it is less than or equal to unity. Meanwhile, $O I$ of the $t+1$ th period is determined by $O C_{t+1} / O C_{t-1 \& t}^{e t+1}$, so that it may be greater than unity (due to technology development) or less than unity (because of no development). The index of the $t+1$ th period implies how much the performance of $t+1$ th period operationally (or technologically) proceeds from the efficiency frontier of the $t-1$ and the $t$ th combined period. Such a difference often exists between the $O E$ and $O I$ measures on the $k$ th DMU at the $t$ th and the $t+1$ th period as well.

\subsubsection{Window Analysis}

Figure 2 describes the window analysis with three annual periods. After visually discussing differences between $O E$ and $O I$ measures in Figure 1, we describe the structure of Figure 2 that depicts the measurement with three periods.

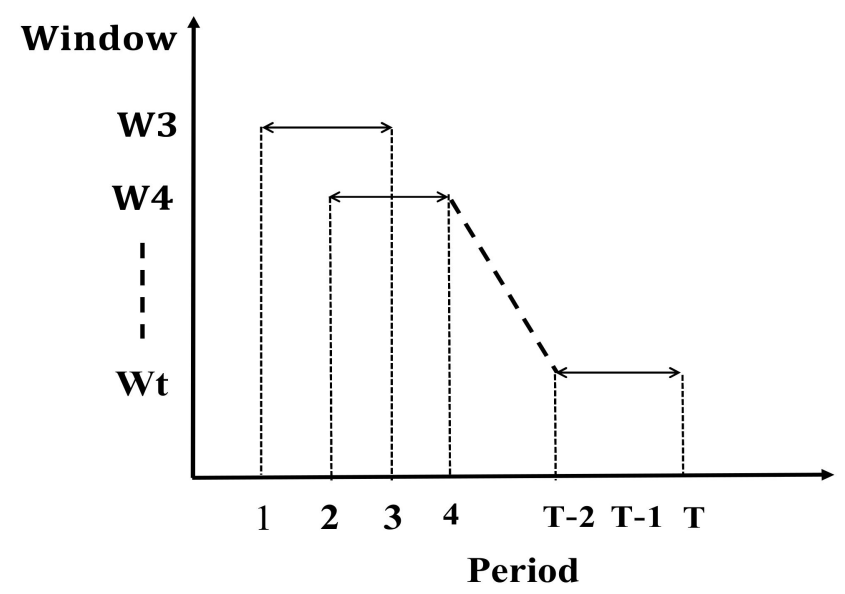

Figure 2. Structure of Window Analysis (with Three Periods). Note: The first window (W3) uses decision-making units (DMUs) under the three periods $(1,2$, and 3$)$ for measurement. The window analysis measures the performance of the $k$ th DMU in the third period as the starting point. The window shifts the length by one period. The index measurement starts DMUs in the fourth period. The window consists of the three periods $(1,2$, and 3), and measures the DMU performance in the fourth period.

The first window consists of observations in the first, second, and third periods in Figure 2. First, we start measuring the degree of $O E$ of the $k$ th DMU from the third period, indicated as W3. The index measure starts from the $k$ th DMU in the fourth period using W3, for a total of four periods in the index analysis. Second, the window consists of the second, third, and fourth periods (W4). In the second window, we measure $O E$ of the $k$ th DMU from the fourth period and index measure for the performance of the DMU in the fifth period. The time shift continues until the window reaches the last period. In that case, the window consists of the T-2 th, T-1 th, and T th periods. We measure the efficiency of the $k$ th DMU at the T th period by Wt consisting of T-2 th, T- 1 th, and $\mathrm{T}$ th periods, and the index measure stops at using the frontier Wt-1 consisting of T- 3 th, T- 2 th, and T- 1 th periods for the $\mathrm{T}$ th performance measurement The description may extend to more than three periods.

There are two other unique features of the index measurement. First, the observations at the $t+1$ th period may be located outside the observed data range of the window, 
comprising the $t-2, t-1$, and $t$ th groups of observations (i.e., DMUs). A difficulty is that the measurement may produce "infeasibility" in a computer code. To avoid the computational difficulty, this study incorporates "constant RTS (Returns to Scale: outputs proportionally increase with inputs." Second, there are many DEA models (e.g., radial, non-radial, and intermediate). This research uses "radial" measure under constant RTS to attain computational feasibility in the window-based index measurement.

\subsection{Cross-Sectional Operational Efficiency (CSOE)}

As the first measure among the three approaches, we assess the $O E$ of utility firms by pooling all observations in a cross-sectional structure. The measure serves as the basis for comparison of the proposed methods. The measurement examines differences in $O E$ and $O I$ among multiple groups and periods. A benefit of the measurement is that it links to statistical (e.g., rank sum) tests that will be discussed in Section 3.6.

This research evaluates each entity as a DMU (a decision making unit, such as a utility firm). In each DMU, the production technology transforms $X$ with $m$ components into $G$ with $s$ components. This study proposes a new type of "radial approach" that determines the levels of $O E$ and $O I$ on the specific $k$ th DMU at the $t$ th period $(t=1, \ldots, T)$.

Given the observed $X_{k t}$ and $G_{k t}$, we evaluate the performance of each DMU. The following formulation measures the degree of $\left(C S O E_{k t}^{c}\right)$ on the $k$ th DMU at the $t$ th period:

$$
\begin{aligned}
\text { Maximize } & \xi+\varepsilon_{s}\left(\sum_{i=1}^{m} R_{i}^{x} d_{i t}^{x}+\sum_{r=1}^{s} R_{r}^{g} d_{r t}^{g}\right) \\
\text { s.t. } & \sum_{t=1}^{T} \sum_{j=1}^{n} x_{i j t} \lambda_{j t}+d_{i t}^{x}+\xi x_{i k t}=x_{i k t} \quad(i=1, \ldots, m \& t: \text { specific }), \\
& \sum_{t=1}^{T} \sum_{j=1}^{n} g_{r j t} \lambda_{j t}-d_{r t}^{g}-\xi g_{r k t}=g_{r k t} \quad(r=1, \ldots, s \& t: \text { specific }), \\
& \lambda_{j t} \geq 0(j=1, \ldots, n \& t=1, \ldots, T), \xi: U R S \\
& d_{i t}^{x} \geq 0(i=1, \ldots, m \& t=1, \ldots, T) \& \\
& d_{r t}^{g} \geq 0(r=1, \ldots, s \& t=1, \ldots, T)
\end{aligned}
$$

It is important to note that the symbol ( $t)$ in the left hand side of Model (1) is used to function for the sum of $t=1, \ldots, T$ (all periods). Meanwhile, the symbol of the right hand side indicates a "specific" period $(t=1, \ldots, T)$ to be examined by Model (1). Thus, both are different as found in the two symbols ( $j$ : all DMUs and $k$ : a specific DMU). It may be better for us to use " $z$ ", not " $t$ " to specify the period to be examined. However, to maintain academic consistency with previous studies, we use "specific" in the right hand side of Model (1).

This study specifies the following two types of data ranges $(\mathrm{R})$ according to the upper and lower bounds of production factors:

$$
\begin{aligned}
& R_{i}^{x}=(m+s)^{-1}\left(\max _{j, t}\left\{x_{i j t} \mid j=1, \ldots, n \& t=1, \ldots, T\right\}-\min _{j, t}\left\{x_{i j t} \mid j=1, \ldots, n \& t=1, \ldots, T\right\}\right)^{-1} \text { and } \\
& R_{r}^{g}=(m+s)^{-1}\left(\max _{j, t}\left\{g_{r j t} \mid j=1, \ldots, n \& t=1, \ldots, T\right\}-\min _{j, t}\left\{g_{r j t} \mid j=1, \ldots, n \& t=1, \ldots, T\right\}\right)^{-1}
\end{aligned}
$$

The purpose of these ranges is that DEA results can avoid an occurrence of zero in multipliers. Such an occurrence implies that corresponding production factors ( $X$ and $G$ ) are not fully utilized in the evaluation. The subscript $(j)$, not $k$ th, is used to express all DMUs $(j=1, \ldots, n)$. Meanwhile, the subscript $(k)$ indicates the specific DMU currently evaluated as mentioned previously. The shape of Model (1) forms constant RTS because it does not incorporate $\sum_{j=1}^{n} \lambda_{j t}=1$ as a side constraint in Model (1).

The degree of $C S O E_{i t}^{c}$ of the $k$ th DMU in the $t$ th period is measured by:

$$
\mathrm{CSOE}_{k t}^{c}=1-\left[\xi^{*}+\varepsilon_{s}\left(\sum_{i=1}^{m} R_{i}^{x} d_{i t}^{x *}+\sum_{r=1}^{s} R_{r}^{g} d_{r t}^{g *}\right)\right]
$$

where the superscript $(c)$ stands for "constant RTS." The inefficiency measure $(\xi)$ and all slack variables $\left(d_{i t}^{x}\right.$ and $\left.d_{r t}^{g}\right)$ are determined on the optimality $\left(^{*}\right)$ of Model (1). We obtain the equation within the parenthesis from the optimality of Model (1). The degree is obtained by subtracting the degree from unity as specified in Equation (2). 


\subsection{Window Analysis for Operational Efficiency (WOE)}

A difficulty of the $O E$ measurement is that all firms are assumed to access an efficiency frontier in the future, which indicates a problem. For example, the structure of Model (1) accepts that utility firms in 2002 may access technology in 2018. Usually, the assumption is unacceptable, thereby indicating a drawback of Model (1).

To overcome the drawback, we modify Model (1) by considering a recent time horizon called a "window." As the second measure, this study proposes the following windowbased formulation to measure the level of $W O E_{k t}^{c}$ on the $k$ th DMU at the $t$ th period:

$$
\begin{aligned}
\text { Maximize } & \xi+\varepsilon_{s}\left(\sum_{i=1}^{m} R_{i}^{x} d_{i t}^{x}+\sum_{r=1}^{s} R_{r}^{g} d_{r t}^{g}\right) \\
\text { s.t. } & \sum_{j \in W_{t}} x_{i j t} \lambda_{j t}+d_{i t}^{x}+\xi x_{i k t}=x_{i k t}(i=1, \ldots, m \& t: \text { specific }), \\
& \sum_{j \in W_{t}} g_{r j t} \lambda_{j t}-d_{r t}^{g}-\xi g_{r k t}=g_{r k t} \quad(r=1, \ldots, s \& t: \text { specific }), \\
& \lambda_{j t} \geq 0(j=1, \ldots, n \& t: \text { specific }), \xi: \text { URS, } \\
& d_{i t}^{x} \geq 0(i=1, \ldots, m \& t: \text { specific }) \& \\
& d_{r t}^{g} \geq 0(r=1, \ldots, s \& t: \text { specific }) .
\end{aligned}
$$

The $W t$ is referred to as a "window length" that indicates multiple periods before the specific $t$ th period, as depicted in Figure 2. The left side (i.e., $\sum_{j \in W_{t}} x_{i j t} \lambda_{j t}$ and $\sum_{j \in W_{t}} g_{r j t} \lambda_{j t}$ ) of Model (3) indicates an efficiency frontier in the window (Wt).

The degree of $W O E_{k t}^{c}$ of the $k$ th DMU at the $t$ period is measured by:

$$
W O E_{k t}^{c}=1-\left[\xi^{*}+\varepsilon_{s}\left(\sum_{i=1}^{m} R_{i}^{x} d_{i t}^{x *}+\sum_{r=1}^{s} R_{r}^{g} d_{r t}^{g *}\right)\right],
$$

where the inefficiency measure $(\xi)$ and all slack variables $\left(d_{i t}^{x}\right.$ and $\left.d_{r t}^{g}\right)$ within the parenthesis are determined on the optimality $\left({ }^{*}\right)$ of Model (3). Equation (4) determines the degree of efficiency by subtracting the level from unity.

\subsection{Window Analysis for Operational Index (WOI)}

As the last measure among three, we propose the following formulation to measure the degree of $W O I_{k t}^{c}$ on the $k$ th DMU at the $t+1$ th period:

$$
\begin{aligned}
\text { Maximize } & \xi+\varepsilon_{s}\left(\sum_{i=1}^{m} R_{i}^{x} d_{i t+1}^{x}+\sum_{r=1}^{s} R_{r}^{g} d_{r t+1}^{g}\right) \\
\text { s.t. } & \sum_{j \in W_{t}} x_{i j t} \lambda_{j t}+d_{i t+1}^{x}+\xi x_{i k t+1}=x_{i k t+1}(i=1, \ldots, m \& t: \text { specific }), \\
& \sum_{j \in W_{t}} g_{r j t} \lambda_{j t}-d_{r t+1}^{g}-\xi g_{r k t+1}=g_{r k t+1}(r=1, \ldots, s \& t: \text { specific }), \\
& \lambda_{j t} \geq 0(j=1, \ldots, n \& t: \text { specific }), \quad \xi: \text { URS, } \\
& d_{i t+1}^{x} \geq 0(i=1, \ldots, m \& t: \text { specific }) \& \\
& d_{r t+1}^{g} \geq 0(r=1, \ldots, s \& t: \text { specific }) .
\end{aligned}
$$

Model (5) replaces the production factors by $x_{i k t+1}$ and $g_{r k t+1}$ of the $t+1$ th period. There is no other difference between Models (3) and (5). The purpose of Model (5) is to measure the degree of index $(O I)$ of the $k$ th DMU at the $t+1$ th period. Model (5) evaluates the performance of DMUs at the $t+1$ th period by using the efficiency frontier in the window, which is a combined frontier with three periods among the $t-2$ th, $t-1$ th, and $t$ th periods.

Model (5) determines the degree of $W O I_{k t+1}^{c}$ as follows:

$$
\mathrm{WOI}_{k t+1}^{c}=1-\left[\xi^{*}+\varepsilon_{s}\left(\sum_{i=1}^{m} R_{i}^{x} d_{i t+1}^{x *}+\sum_{r=1}^{s} R_{r}^{g} d_{r t+1}^{g^{*}}\right)\right],
$$

The inefficiency measure and all slack variables are determined on the optimality of Model (5). The equation within the parenthesis is obtained from the optimality of Model (5).

There are two noteworthy comments on Model (5). First, since $\xi^{*}$ is unrestricted, the value in the parenthesis may be negative. In that case, WOI ${ }_{k t+1}^{c}$ becomes greater 
than unity in the degree. Meanwhile, $W O E_{k t}^{c}$ is always less than or equal to unity. The degree of $W O I_{k t+1}^{c}$, greater than unity indicates an economic and/or technological progress in the production process by a shift from the $t$ th to the $t+1$ th period. Second, the proposed three models do not consider variable RTS in their structures. In particular, the index measurement needs to assume constant RTS. Without the assumption, the index measurement of Model (5) may produce an infeasible solution. To avoid this, we assume constant RTS in the index measurement and the treatment extends to all models that do not have $\sum_{j \in W_{t}} \lambda_{j t}=1$, implying variable RTS, in their formulations.

\subsection{Analytical Features}

This research has developed the three new DEA approaches over time. They are different from standard DEA models, as found in unique features. Some of them are specified as follows:

(a) Data ranges: The proposed three approaches incorporate the two types of data ranges (R) into the objective function of their formulations. Meanwhile, the standard models often do not have any influence (i.e., ranges) from slacks in their efficiency measures. An exception is the incorporation of a non-Archimedean small number. A problem of the standard models is that dual variable, or so called multipliers (implying weights among inputs and outputs), may become "zero". This indicates that production factors are not fully used in the standard assessment. This is unacceptable. It is true that if we include the non-Archimedean small number, then we can solve the difficulty. However, none can determine the reasonable magnitude of the small number. This is another problem. The proposed approaches can solve the difficulty.

(b) Unique projection: A benefit of the proposed approaches is that they have a unique projection from inefficiency to efficiency because their projections are specified by a directional vector $\left(x_{i k t}, g_{r k t}\right)$. Meanwhile, the standard models may suffer from a possible occurrence of multiple projections (so, multiple reference sets as well).

(c) OE measures: The standard models are usually classified into input or output-based measures so that both produce different degrees in $O E$ measures, while the proposed approaches do not have such classification, or orientation, to determine the level of $O E$ in Models (1) and (3) by combing inputs and outputs with the inefficiency score $(\xi)$. This is an innovative approach that provides a degree of the OE measure (as CSOE and $W O E$ ), not depending on the type (input or output orientation) of production factors. The feature may be applicable to WOI, as well.

(d) Degree of measures: The proposed approaches measure the degree of inefficiency with the score $(\xi)$, hence the degree of CSOE, WOE, and WOI is obtained by subtracting the level of inefficiency from unity. This feature is different from the standard models that measure the degree of efficiency (not inefficiency).

(e) Difference among (3) and (5): As an alternative of Model (1), the other two approaches calculate the degree of inefficiency (Model (3)) and that of index (Model (5)). Both belong to the window analysis with different features. For example, Model (3) produces the degree of WOE between 0 and 1, while Model (5) measures that of WOI which may become more than 1 , indicating a technological progress. The other difference can be found in the directional vectors in different periods. For instance, Model (3) incorporates the directional vector $\left(x_{i k t}, g_{r k t}\right)$ of the $t$ th period while Model (5) incorporates the vector $\left(x_{i k t+1}, g_{r k t+1}\right)$ of the $t+1$ th period, as specified in the right hands of these formulations. Thus, WOE measures an efficiency shift while WOI measures total measure, including the technology progress over time.

(f) Efficiency shift: Standard models measure a frontier shift among multiple periods by assuming that DMUs in the past can access technology in the future. The assumption may be slightly acceptable. On the other hand, the approaches employed by Models (3) and (5) measure an efficiency shift, not the frontier shift, so that we can avoid the assumption. 
(g) Computational concerns: First, the score $(\xi)$ is unrestricted so that the index measure (6) can produce a degree more than unity. Second, the three approaches drop $\sum_{j=1}^{n} \lambda_{j t}=1$ as a side constraint to avoid computational infeasibility. What happens if we incorporate the constraint? For example, Model (5) may produce an infeasible solution on a computer code. Hence, we need to assume constant RTS in measuring WOI. Models (1) and (3) do not have such a computational difficulty in measuring both CSOE and WOE. If necessary, we can solve both models under variable RTS.

(h) Discriminant capability: When a sample size is relatively small, the standard models usually produce many efficient DMUs so that they do not have any discriminant capability. The drawback is applicable to the proposed models ((1), (3), and (5)). An approach to handle the difficulty is that we take their dual formulations and then allocate restriction on dual variables (i.e., multipliers), by prior or mathematical information. This type of research will be an important future task.

Thus, Models (1), (3), and (5) provide us with novel efficiency and index measures as new approaches, which cannot be found in previous studies. However, such an extension is only one step toward our methodological betterment in DEA.

\subsection{Rank Sum Tests}

A difficulty in applying DEA to real world situations is that it does not have statistical inference, because it does not have a statistical capability. That is a shortcoming. To overcome the difficulty, we utilize two rank sum tests.

First, to examine the null hypothesis (i.e., no difference between two groups), we use the Mann-Whitney rank sum test for electricity and gas firms in terms of operational efficiencies (i.e., CSOE). In the test, all firms are ranked by their $C S O E_{k t}^{c}$ scores from greatest to least. The equations used for the test are as follows:

$$
U=(n 1 \times n 2)+\frac{n 1(n 1+1)}{2}-\sum R_{1} \text { or } U=(n 1 \times n 2)+\frac{n 2(n 2+1)}{2}-\sum R_{2},
$$

where $n 1$ and $n 2$ represent the number of firms in the first and second group, respectively, and $\sum R_{1}$ and $\sum R_{2}$ indicate the sum of the ranks, respectively.

It is mathematically approximated that each group follows a normal distribution that has a mean expressed as $n 1 n 2 / 2$ and a variance expressed as $n 1 n 2(n 1+n 2+1) / 12$. The test statistic becomes as follows:

$$
\mu=\left[U-\frac{n 1 n 2}{2}\right] / \sqrt{n 1 n 2(n 1+n 2+1) / 12} .
$$

It follows a standard normal distribution $\mathrm{N}(0,1)$.

To examine the other null hypothesis (e.g., no difference among multiple periods), we use the Kruskal-Wallis rank sum test. In the test, the entire observed periods are separated into $T$ periods to examine whether there is difference among multiple periods. We apply the rank sum test based on efficiency scores.

To compute the Kruskal-Wallis statistic ( $H$ score), we combine all observations $\left(n=\sum_{t=1}^{T} n_{t}\right)$ in $T$ th periods to examine annual differences among them. The $n$ stands for the number, and the subscript $(t)$ indicates the $t$ th period. Then, we rank them from greatest to least by these efficiency scores over the entire period. Let $R_{j t}$ denote the rank of the $j$ th company in the $t$ th period. The rank sum of all companies in the $t$ th period is $R_{t}=\sum_{j=1}^{n_{t}} R_{j t}$. The $H$ score is determined by:

$$
H=\frac{12}{n(n+1)} \sum_{t=1}^{T} \frac{R_{t}^{2}}{n_{t}}-3(n+1) .
$$

The statistic $(H)$ follows the $\chi^{2}$ distribution with a degree of freedom $(d f=T-1)$. 


\section{Empirical Study}

This study has sampled nine electricity and two gas companies in Japan as utility companies. The number of observations is 11 firms over 17 years that becomes 187 DMUs as like cross-sectional data in Model (1), and 33 DMUs in a three-year window in Models (3) and (5). Each sample has seven production factors (i.e., three inputs and four outputs).

The source of the data set was S\&P Capital IQ, except the number of patent applications, which were obtained from World Intellectual Property Organization, Patentscope. Sample periods were fiscal years 2002-2018.

The nine electricity companies were the Hokkaido Electric Power Company, Tohoku Electric Power Company, Tokyo Electric Power Company, Chubu Electric Power Company, Hokuriku Electric Power Company, Kansai Electric Power Company, Chugoku Electric Power Company, Shikoku Electric Power Company, and the Kyushu Electric Power Company. The two gas companies were the Tokyo Gas Company and Osaka Gas Company.

All firms were evaluated by inputs and outputs. Inputs were total assets (million Japanese Yen (JPY)), capital expenditure (million JPY), and total operating expenditure (million JPY). Outputs were total revenue (million JPY), Earnings Before Interest, Taxes, Depreciation, and Amortization (EBITDA) (million JPY), total enterprise value (million JPY), and number (\#) of patent applications. The number of patent applications is an output because it expresses future growth potential for companies by technological development.

It is important to note the following three concerns on the selection of these production factors: First, the operating expenditure contains the cost of fuel to generate electricity and gas, which is a major intermediate consumption in the production process of electricity and gas industries. On the other hand, the total revenue shows the gross amount of total sales. It serves as an output. Thus, by balancing both as an input and an output, we implicitly incorporate the concept of "operating profit" in our assessment. In the selection process, we avoid a data item with zero and negative values, which sometimes appear in the operating profit and cause a computational difficulty in DEA. The proposed selection of data is useful to avoid such difficulty. Second, it is necessary to discuss that the EBITDA is very important for performance assessment of electricity and gas industries. The EBITDA is a profit account of firms and represents earning power in their core business, because it is calculated as the operating profit plus depreciation/amortization of plants and equipment. The rationale on why the depreciation/amortization is added back to the operating profit is that it is a non-expendable expense so that it can be considered as part of earning power of firms. In addition, the depreciation/amortization generally becomes a large amount in electricity and gas industries since they are a traditional equipment industry, usually investing in large amount capital assets to establish production processes, thereby it is not negligible in the assessment of the industries. Furthermore, EBITDA and total revenue are related each other, but they are not in a double counting relationship because the former is a kind of profit (net account) and the latter is a total sales (gross account), both of which provide useful information for our performance assessment.

Finally, the total enterprise value is not included in SNA (System of National Accounts). The measure is usually not considered as an output. However, we treat it as the output because it represents the expectation of a stock market for future growth potential of firms. The expectation becomes more influential on corporate management than before under the globalized financial market. Therefore, the incorporation is acceptable and important for the proposed performance assessment.

Table 1 summarizes the descriptive statistics on the data set. Table 2 summarizes the $C S O E_{k t}^{c}$ score of 11 utility firms measured by Model (1). We pooled all annual periods (2002-2018) and treated it as cross-sectional data. Figure 3 depicts the average trends of the two groups of utility firms, showing that the operational efficiencies of gas companies have outperformed those of electric power companies. In particular, this research notes the $C S O E_{k t}^{c}$ of electric power companies from 2011 to 2013. The disaster of the Fukushima 
Daiichi Nuclear Power Plant significantly impacted their efficiency measures. The gas industry did not experience a similar influence in the observed periods.

Table 1. Descriptive Statistics (2002-2018).

\begin{tabular}{|c|c|c|c|c|c|c|c|c|}
\hline \multicolumn{2}{|c|}{ Production Factors } & $\begin{array}{c}\text { Total } \\
\text { Revenue }\end{array}$ & EBITDA & $\begin{array}{c}\text { Total } \\
\text { Enterprise } \\
\text { Value } \\
\end{array}$ & $\begin{array}{l}\text { Number } \\
\text { of } \\
\text { Patents }\end{array}$ & $\begin{array}{l}\text { Total } \\
\text { Assets }\end{array}$ & $\begin{array}{c}\text { Capital } \\
\text { Expenditure }\end{array}$ & $\begin{array}{c}\text { Total } \\
\text { Operating } \\
\text { Cost }\end{array}$ \\
\hline \multicolumn{2}{|l|}{ Unit } & $\begin{array}{l}\text { Million } \\
\text { JPY }\end{array}$ & $\begin{array}{l}\text { Million } \\
\text { JPY }\end{array}$ & $\begin{array}{l}\text { Million } \\
\text { JPY }\end{array}$ & $\#$ & $\begin{array}{l}\text { Million } \\
\text { JPY }\end{array}$ & Million JPY & Million JPY \\
\hline \multirow{4}{*}{$\begin{array}{l}\text { Hokkaido } \\
\text { EPCo }\end{array}$} & Avg. & 597,872 & 121,082 & $1,284,276$ & 12 & $1,626,006$ & 116,017 & 570,678 \\
\hline & Max. & 733,050 & 177,371 & $1,477,960$ & 20 & $1,915,908$ & 165,091 & 710,509 \\
\hline & Min. & 517,204 & $(17,921)$ & $1,120,832$ & 2 & $1,435,924$ & 86,544 & 433,945 \\
\hline & S.D. & 74,723 & 55,947 & 107,186 & 4 & 158,169 & 24,272 & 106,652 \\
\hline \multirow{4}{*}{$\begin{array}{l}\text { Tohoku } \\
\text { EPCo }\end{array}$} & Avg. & $1,805,100$ & 360,395 & $3,188,605$ & 37 & $4,134,503$ & 254,681 & $1,701,958$ \\
\hline & Max. & $2,182,075$ & 527,271 & $3,628,550$ & 60 & $4,299,782$ & 293,809 & $2,012,335$ \\
\hline & Min. & $1,562,752$ & 95,163 & $2,534,132$ & 25 & $3,918,574$ & 199,853 & $1,383,789$ \\
\hline & S.D. & 193,292 & 106,463 & 310,357 & 10 & 102,072 & 31,054 & 210,256 \\
\hline \multirow{4}{*}{$\begin{array}{l}\text { Tokyo } \\
\text { EPCo }\end{array}$} & Avg. & $5,551,127$ & $1,052,909$ & $9,299,157$ & 272 & $13,930,729$ & 650,586 & $5,246,243$ \\
\hline & Max. & $6,802,464$ & $1,612,370$ & $12,367,949$ & 432 & $15,536,456$ & 894,572 & $6,485,929$ \\
\hline & Min. & $4,853,826$ & 399,092 & $5,674,767$ & 79 & $12,277,600$ & 544,157 & $4,364,821$ \\
\hline & S.D. & 569,903 & 349,280 & $2,641,280$ & 132 & 844,034 & 94,858 & 713,832 \\
\hline \multirow{4}{*}{$\begin{array}{l}\text { Chubu } \\
\text { EPCo }\end{array}$} & Avg. & $2,462,990$ & 518,257 & $4,415,322$ & 82 & $5,711,112$ & 268,401 & $2,276,672$ \\
\hline & Max. & $3,103,604$ & 797,704 & $5,623,518$ & 156 & $6,435,215$ & 416,631 & $2,996,435$ \\
\hline & Min. & $2,101,072$ & 218,054 & $3,427,955$ & 21 & $5,299,976$ & 145,364 & $1,766,659$ \\
\hline & S.D. & 308,374 & 185,945 & 903,724 & 46 & 310,920 & 67,216 & 403,232 \\
\hline \multirow{4}{*}{$\begin{array}{l}\text { Hokuriku } \\
\text { EPCo }\end{array}$} & Avg. & 502,634 & 129,657 & $1,228,138$ & 16 & $1,502,855$ & 77,039 & 461,850 \\
\hline & Max. & 596,283 & 194,133 & $1,533,038$ & 29 & $1,603,728$ & 117,322 & 581,457 \\
\hline & Min. & 451,466 & 75,382 & 979,338 & 5 & $1,381,163$ & 41,131 & 393,071 \\
\hline & S.D. & 35,613 & 38,337 & 217,075 & 9 & 79,656 & 22,634 & 52,225 \\
\hline \multirow{4}{*}{$\begin{array}{l}\text { Kansai } \\
\text { EPCo }\end{array}$} & Avg. & $2,837,997$ & 580,919 & $5,290,014$ & 136 & $7,218,646$ & 387,658 & $2,678,693$ \\
\hline & Max. & $3,406,030$ & 850,255 & $6,114,891$ & 272 & $7,777,519$ & 491,956 & $3,484,630$ \\
\hline & Min. & $2,540,155$ & 75,095 & $4,610,550$ & 20 & $6,789,605$ & 276,629 & $2,190,663$ \\
\hline & S.D. & 282,716 & 233,938 & 411,357 & 92 & 342,731 & 67,222 & 424,838 \\
\hline \multirow{4}{*}{$\begin{array}{l}\text { Chugoku } \\
\text { EPCo }\end{array}$} & Avg. & $1,130,802$ & 204,435 & $2,336,463$ & 643 & $2,862,839$ & 154,007 & $1,065,660$ \\
\hline & Max. & $1,314,967$ & 312,215 & $2,514,105$ & 1,108 & $3,179,442$ & 214,038 & $1,275,341$ \\
\hline & Min. & 967,056 & 108,836 & $2,109,853$ & 67 & $2,636,363$ & 101,092 & 867,470 \\
\hline & S.D. & 109,437 & 65,625 & 114,573 & 284 & 168,658 & 35,347 & 142,432 \\
\hline \multirow{4}{*}{$\begin{array}{l}\text { Shikoku } \\
\text { EPCo }\end{array}$} & Avg. & 611,512 & 125,519 & $1,166,296$ & 11 & $1,400,364$ & 69,957 & 572,919 \\
\hline & Max. & 731,775 & 193,851 & $1,419,244$ & 20 & $1,515,185$ & 89,063 & 702,510 \\
\hline & Min. & 545,393 & 19,125 & 926,906 & 3 & $1,301,267$ & 57,429 & 501,905 \\
\hline & S.D. & 50,387 & 46,662 & 174,309 & 6 & 48,813 & 8,618 & 63,608 \\
\hline
\end{tabular}


Table 1. Cont.

\begin{tabular}{ccccccccc}
\hline Production Factors & $\begin{array}{c}\text { Total } \\
\text { Revenue }\end{array}$ & EBITDA & $\begin{array}{c}\text { Total } \\
\text { Enterprise } \\
\text { Value }\end{array}$ & $\begin{array}{c}\text { Number } \\
\text { of } \\
\text { Patents }\end{array}$ & $\begin{array}{c}\text { Total } \\
\text { Assets }\end{array}$ & $\begin{array}{c}\text { Capital } \\
\text { Expenditure }\end{array}$ & $\begin{array}{c}\text { Total } \\
\text { Operating } \\
\text { Cost }\end{array}$ \\
\hline \multirow{2}{*}{ Unit } & & $\begin{array}{c}\text { Million } \\
\text { JPY }\end{array}$ & $\begin{array}{c}\text { Million } \\
\text { JPY }\end{array}$ & $\begin{array}{c}\text { Million } \\
\text { JPY }\end{array}$ & \# & $\begin{array}{c}\text { Million } \\
\text { JPY }\end{array}$ & Million JPY & Million JPY \\
\hline \multirow{2}{*}{ Kyushu } & Avg. & $1,574,684$ & 316,301 & $3,235,075$ & 29 & $4,326,199$ & 253,889 & $1,502,311$ \\
EPCo & Max. & $1,960,359$ & 492,172 & $3,572,286$ & 65 & $4,784,735$ & 352,763 & $1,916,782$ \\
& Min. & $1,391,684$ & $(86,693)$ & $2,670,354$ & 4 & $4,038,838$ & 183,922 & $1,192,718$ \\
& S.D. & 195,845 & 165,269 & 280,627 & 19 & 272,244 & 49,874 & 273,621 \\
\hline Tokyo & Avg. & $1,566,680$ & 265,282 & $1,765,412$ & 198 & $1,902,742$ & 137,596 & $1,444,546$ \\
GasCo & Max. & $2,292,548$ & 337,195 & $2,148,394$ & 343 & $2,334,721$ & 195,060 & $2,120,793$ \\
& Min. & $1,097,589$ & 202,714 & $1,472,495$ & 118 & $1,666,828$ & 94,084 & 986,981 \\
S.D. & 355,171 & 38,847 & 219,173 & 64 & 247,957 & 31,644 & 346,360 \\
\hline Osaka & Avg. & $1,203,236$ & 183,553 & $1,230,712$ & 368 & $1,512,380$ & 88,161 & $1,110,533$ \\
GasCo & Max. & $1,528,164$ & 238,792 & $1,490,790$ & 700 & $1,905,215$ & 115,244 & $1,423,098$ \\
& Min. & 947,978 & 153,482 & 870,287 & 253 & $1,199,229$ & 64,800 & 859,228 \\
\hline
\end{tabular}

Note: The statistics are obtained from the performance of each firm during 2002-2018. For example, the Avg. (average) is obtained from the periods. Mix, Min and S.D. stand for maximum, minimum and standard deviation. The number of DMUs is 11 firms over 17 years that becomes 187 in total. Each sample has seven production factors (i.e., three inputs and four outputs).

Table 2. Cross-Sectional Operational Efficiencies (CSOE) of Utility Companies: Pooled Data.

\begin{tabular}{|c|c|c|c|c|c|c|c|c|c|c|c|c|c|c|c|c|c|c|}
\hline Company & 2002 & 2003 & 2004 & 2005 & 2006 & 2007 & 2008 & 2009 & 2010 & 2011 & 2012 & 2013 & 2014 & 2015 & 2016 & 2017 & 2018 & Avg. \\
\hline $\begin{array}{c}\text { Hokkaido } \\
\text { EPCo }\end{array}$ & 0.980 & 0.984 & 0.999 & 1.000 & 0.977 & 0.983 & 0.956 & 0.904 & 0.943 & 0.952 & 0.921 & 0.869 & 0.863 & 0.922 & 0.948 & 0.937 & 0.940 & 0.946 \\
\hline $\begin{array}{c}\text { Tohoku } \\
\text { EPCo }\end{array}$ & 0.981 & 0.981 & 0.975 & 0.969 & 0.950 & 0.959 & 0.944 & 0.923 & 0.947 & 0.954 & 0.882 & 0.906 & 0.945 & 0.965 & 0.971 & 0.957 & 0.950 & 0.950 \\
\hline $\begin{array}{l}\text { Tokyo } \\
\text { EPCo }\end{array}$ & 0.979 & 0.968 & 0.966 & 0.973 & 0.973 & 0.973 & 0.932 & 0.927 & 0.946 & 0.953 & 0.892 & 0.903 & 0.937 & 0.950 & 0.953 & 0.946 & 0.948 & 0.948 \\
\hline $\begin{array}{l}\text { Chubu } \\
\text { EPCo }\end{array}$ & 0.992 & 0.989 & 0.998 & 1.000 & 1.000 & 0.989 & 0.956 & 0.959 & 0.965 & 0.959 & 0.915 & 0.920 & 0.917 & 0.949 & 0.976 & 0.950 & 0.949 & 0.964 \\
\hline $\begin{array}{c}\text { Hokuriku } \\
\text { EPCo }\end{array}$ & 1.000 & 1.000 & 1.000 & 1.000 & 1.000 & 0.984 & 1.000 & 0.953 & 0.957 & 0.966 & 0.928 & 0.927 & 0.935 & 0.953 & 0.950 & 0.925 & 0.929 & 0.965 \\
\hline $\begin{array}{c}\text { Kansai } \\
\text { EPCo }\end{array}$ & 0.976 & 0.979 & 0.987 & 0.994 & 0.982 & 0.970 & 0.953 & 0.925 & 0.959 & 0.966 & 0.881 & 0.869 & 0.912 & 0.912 & 0.961 & 0.958 & 0.958 & 0.950 \\
\hline $\begin{array}{c}\text { Chugoku } \\
\text { EPCo }\end{array}$ & 0.975 & 0.985 & 0.984 & 1.000 & 1.000 & 0.986 & 0.970 & 0.941 & 0.968 & 0.952 & 0.952 & 0.927 & 0.932 & 0.953 & 0.945 & 0.936 & 0.938 & 0.961 \\
\hline $\begin{array}{c}\text { Shikoku } \\
\text { EPCo }\end{array}$ & 0.978 & 0.979 & 0.973 & 0.974 & 0.980 & 0.988 & 0.977 & 0.969 & 0.959 & 0.972 & 0.926 & 0.881 & 0.925 & 0.946 & 0.942 & 0.941 & 0.947 & 0.956 \\
\hline $\begin{array}{c}\text { Kyushu } \\
\text { EPCo }\end{array}$ & 0.983 & 0.978 & 0.988 & 0.993 & 0.976 & 0.971 & 0.951 & 0.944 & 0.949 & 0.948 & 0.861 & 0.836 & 0.895 & 0.908 & 0.950 & 0.952 & 0.946 & 0.943 \\
\hline $\begin{array}{l}\text { Tokyo } \\
\text { GasCo }\end{array}$ & 0.986 & 0.990 & 1.000 & 1.000 & 0.996 & 1.000 & 0.976 & 0.979 & 0.969 & 0.986 & 1.000 & 0.997 & 0.998 & 1.000 & 0.996 & 0.954 & 0.972 & 0.988 \\
\hline $\begin{array}{l}\text { Osaka } \\
\text { GasCo }\end{array}$ & 1.000 & 1.000 & 1.000 & 1.000 & 0.988 & 1.000 & 0.982 & 1.000 & 0.984 & 1.000 & 1.000 & 1.000 & 0.996 & 0.988 & 0.994 & 0.983 & 1.000 & 0.995 \\
\hline $\begin{array}{l}\text { Avg. } \\
\text { EPCo }\end{array}$ & 0.983 & 0.983 & 0.985 & 0.989 & 0.982 & 0.978 & 0.960 & 0.938 & 0.955 & 0.958 & 0.906 & 0.893 & 0.918 & 0.940 & 0.955 & 0.945 & 0.945 & 0.954 \\
\hline $\begin{array}{l}\text { Avg. } \\
\text { GasCo }\end{array}$ & 0.993 & 0.995 & 1.000 & 1.000 & 0.992 & 1.000 & 0.979 & 0.990 & 0.977 & 0.993 & 1.000 & 0.998 & 0.997 & 0.994 & 0.995 & 0.969 & 0.986 & 0.992 \\
\hline $\begin{array}{l}\text { Total } \\
\text { Avg. }\end{array}$ & 0.985 & 0.985 & 0.988 & 0.991 & 0.984 & 0.982 & 0.963 & 0.948 & 0.959 & 0.964 & 0.923 & 0.912 & 0.932 & 0.950 & 0.962 & 0.949 & 0.953 & 0.961 \\
\hline
\end{tabular}

Note: (a) EPCo stands for an electric power company. GasCo stands for a gas company. Avg stands for the average of CSOE measures on each industry. (b)The results presented in this table are calculated by using 187 decision-making units (DMUs) as a cross-sectional data structure in Model (1). This is a strong assumption on technological progress over periods from 2002 to 2018, showing a serious drawback of Model (1). This study uses the structure for our statistical tests. 


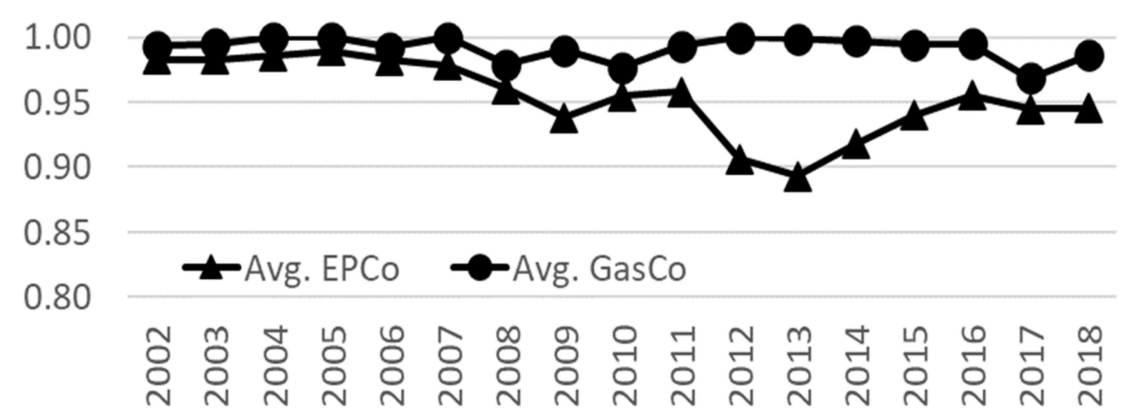

Figure 3. Operational Efficiencies (CSOE) of Utility Companies: Pooled Data. Note: See the bottom of Table 2.

Table 3 measures the window-based operational efficiencies $\left(W O E_{k t}^{c}\right)$ of the utility firms. In the investigation, we prepared a window with three annual periods and gradually shifted the window each year. The first window comprises the first three years, so that the windows shift from 2004 (2002-2004) to 2018 (2016-2018). Figure 4 presents the average time trend of $W O E_{k t}^{c}$ and indicates almost no change in the gas industry. In contrast, the electric power company displayed a change (i.e., decreasing and increasing) from 2005 to 2011 and another change from 2011 to 2016. The first change indicates that the retail market competition due to deregulation and the global financial crisis of 2008 affected the electric power industry. The second change indicates that the industry suffered damage due to the nuclear disaster.

Table 3. Operational Efficiencies (WOE) of Utility Firms: Window Analysis.

\begin{tabular}{|c|c|c|c|c|c|c|c|c|c|c|c|c|c|c|c|c|}
\hline & 2004 & 2005 & 2006 & 2007 & 2008 & 2009 & 2010 & 2011 & 2012 & 2013 & 2014 & 2015 & 2016 & 2017 & 2018 & Avg. \\
\hline $\begin{array}{l}\text { Hokkaido } \\
\text { EPCo }\end{array}$ & 1.000 & 1.000 & 0.977 & 0.983 & 0.962 & 0.918 & 0.984 & 0.986 & 0.950 & 1.000 & 0.982 & 1.000 & 0.993 & 1.000 & 0.997 & 0.982 \\
\hline $\begin{array}{c}\text { Tohoku } \\
\text { EPCo }\end{array}$ & 0.978 & 0.969 & 0.950 & 0.961 & 0.950 & 0.934 & 0.981 & 0.982 & 0.911 & 0.972 & 0.997 & 1.000 & 1.000 & 0.991 & 0.980 & 0.970 \\
\hline $\begin{array}{l}\text { Tokyo } \\
\text { EPCo }\end{array}$ & 0.968 & 0.973 & 0.973 & 0.973 & 0.938 & 0.943 & 0.984 & 0.985 & 0.922 & 0.934 & 0.978 & 0.984 & 0.974 & 0.970 & 0.968 & 0.965 \\
\hline $\begin{array}{l}\text { Chubu } \\
\text { EPCo }\end{array}$ & 1.000 & 1.000 & 1.000 & 0.989 & 0.961 & 0.974 & 1.000 & 0.987 & 0.944 & 0.947 & 0.961 & 0.982 & 1.000 & 0.978 & 0.975 & 0.980 \\
\hline $\begin{array}{l}\text { Hokuriku } \\
\text { EPCo }\end{array}$ & 1.000 & 1.000 & 1.000 & 0.985 & 1.000 & 0.966 & 1.000 & 1.000 & 0.964 & 1.000 & 1.000 & 1.000 & 1.000 & 0.969 & 0.973 & 0.990 \\
\hline $\begin{array}{c}\text { Kansai } \\
\text { EPCo }\end{array}$ & 0.989 & 0.994 & 0.982 & 0.971 & 0.960 & 0.938 & 1.000 & 0.999 & 0.909 & 0.932 & 0.959 & 0.952 & 0.998 & 1.000 & 0.996 & 0.972 \\
\hline $\begin{array}{c}\text { Chugoku } \\
\text { EPCo }\end{array}$ & 1.000 & 1.000 & 1.000 & 0.986 & 0.974 & 0.957 & 1.000 & 0.983 & 0.982 & 1.000 & 0.998 & 1.000 & 0.998 & 1.000 & 1.000 & 0.992 \\
\hline $\begin{array}{c}\text { Shikoku } \\
\text { EPCo }\end{array}$ & 0.975 & 0.974 & 0.982 & 0.988 & 0.977 & 0.982 & 0.995 & 1.000 & 0.958 & 1.000 & 0.976 & 1.000 & 0.972 & 0.978 & 0.977 & 0.982 \\
\hline $\begin{array}{c}\text { Kyushu } \\
\text { EPCo }\end{array}$ & 0.990 & 0.993 & 0.976 & 0.971 & 0.958 & 0.959 & 0.989 & 0.981 & 0.889 & 1.000 & 0.968 & 0.968 & 0.994 & 1.000 & 0.988 & 0.975 \\
\hline $\begin{array}{l}\text { Tokyo } \\
\text { GasCo }\end{array}$ & 1.000 & 1.000 & 1.000 & 1.000 & 1.000 & 1.000 & 0.999 & 1.000 & 1.000 & 1.000 & 1.000 & 1.000 & 1.000 & 1.000 & 1.000 & 1.000 \\
\hline $\begin{array}{l}\text { Osaka } \\
\text { GasCo }\end{array}$ & 1.000 & 1.000 & 0.993 & 1.000 & 1.000 & 1.000 & 1.000 & 1.000 & 1.000 & 1.000 & 1.000 & 1.000 & 1.000 & 1.000 & 1.000 & 1.000 \\
\hline $\begin{array}{l}\text { Avg. } \\
\text { EPCo }\end{array}$ & 0.989 & 0.989 & 0.982 & 0.979 & 0.965 & 0.952 & 0.993 & 0.989 & 0.937 & 0.976 & 0.980 & 0.987 & 0.992 & 0.987 & 0.984 & 0.979 \\
\hline $\begin{array}{l}\text { Avg. } \\
\text { GasCo }\end{array}$ & 1.000 & 1.000 & 0.997 & 1.000 & 1.000 & 1.000 & 1.000 & 1.000 & 1.000 & 1.000 & 1.000 & 1.000 & 1.000 & 1.000 & 1.000 & 1.000 \\
\hline Total Avg. & 0.991 & 0.991 & 0.985 & 0.983 & 0.971 & 0.961 & 0.994 & 0.991 & 0.948 & 0.980 & 0.984 & 0.990 & 0.994 & 0.990 & 0.987 & 0.983 \\
\hline
\end{tabular}




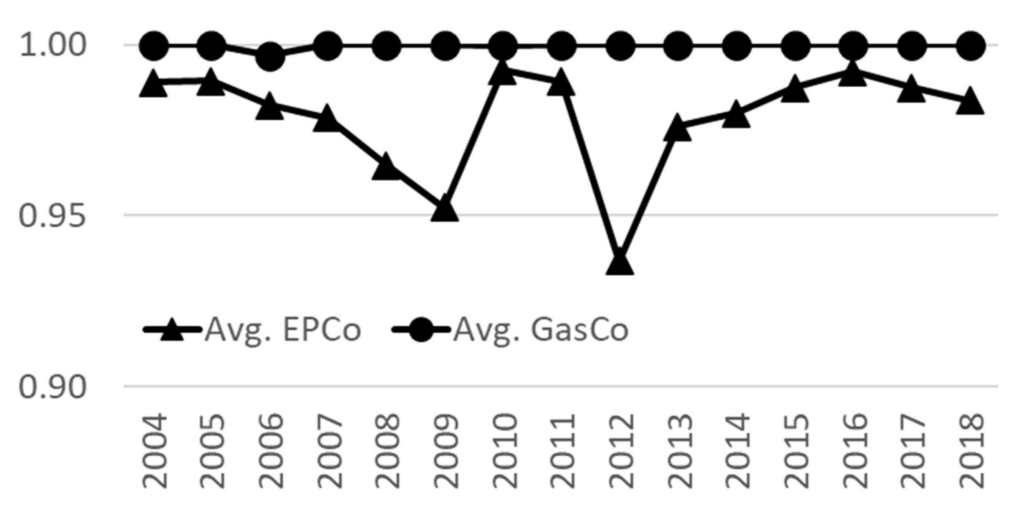

Figure 4. Operational Efficiency (WOE) of Utility Companies: Window Analysis. Note: See the bottom of Tables 2 and 3.

Table 4 summarizes the window-based operational index (WOI $I_{k t+1}^{c}$ ) of 11 utility firms from 2005 to 2018. The study uses a window with three annual periods from 2004 to 2017 that measures the performance of the period from 2005 to 2018. Figure 5 illustrates fluctuations in the averages of the electricity and gas firms. The gas industry exhibited greater than unity in most periods, while the electricity industry showed less than unity.

Table 4. Operational Index (WOI) of Utility Companies: Index Measurement.

\begin{tabular}{|c|c|c|c|c|c|c|c|c|c|c|c|c|c|c|c|}
\hline & 2005 & 2006 & 2007 & 2008 & 2009 & 2010 & 2011 & 2012 & 2013 & 2014 & 2015 & 2016 & 2017 & 2018 & Avg. \\
\hline $\begin{array}{c}\text { Hokkaido } \\
\text { EPCo }\end{array}$ & 1.003 & 0.977 & 0.983 & 0.957 & 0.910 & 0.962 & 0.994 & 0.949 & 0.953 & 0.975 & 1.020 & 0.993 & 1.011 & 0.995 & 0.977 \\
\hline $\begin{array}{c}\text { Tohoku } \\
\text { EPCo }\end{array}$ & 0.972 & 0.951 & 0.959 & 0.947 & 0.929 & 0.960 & 0.988 & 0.910 & 0.941 & 0.979 & 1.043 & 1.067 & 0.991 & 0.979 & 0.973 \\
\hline $\begin{array}{l}\text { Tokyo } \\
\text { EPCo }\end{array}$ & 0.984 & 0.973 & 0.974 & 0.934 & 0.933 & 0.965 & 0.992 & 0.922 & 0.934 & 0.969 & 0.984 & 0.991 & 0.970 & 0.968 & 0.964 \\
\hline $\begin{array}{l}\text { Chubu } \\
\text { EPCo }\end{array}$ & 1.277 & 1.016 & 0.990 & 0.958 & 0.965 & 0.983 & 0.992 & 0.944 & 0.947 & 0.945 & 0.986 & 1.079 & 0.978 & 0.975 & 1.003 \\
\hline $\begin{array}{c}\text { Hokuriku } \\
\text { EPCo }\end{array}$ & 1.045 & 1.049 & 0.985 & 1.010 & 0.953 & 0.985 & 1.026 & 0.964 & 0.963 & 0.989 & 1.073 & 1.009 & 0.970 & 0.972 & 0.999 \\
\hline $\begin{array}{l}\text { Kansai } \\
\text { EPCo }\end{array}$ & 0.997 & 0.982 & 0.970 & 0.955 & 0.931 & 0.977 & 1.007 & 0.909 & 0.904 & 0.939 & 0.960 & 1.037 & 1.036 & 0.996 & 0.971 \\
\hline $\begin{array}{c}\text { Chugoku } \\
\text { EPCo }\end{array}$ & 1.214 & 1.017 & 0.988 & 0.970 & 0.946 & 1.004 & 0.984 & 0.982 & 1.017 & 0.995 & 1.012 & 0.997 & 1.005 & 0.995 & 1.009 \\
\hline $\begin{array}{c}\text { Shikoku } \\
\text { EPCo }\end{array}$ & 0.982 & 0.997 & 0.992 & 0.977 & 0.971 & 0.976 & 1.041 & 0.955 & 0.964 & 0.962 & 1.039 & 0.979 & 0.982 & 0.972 & 0.985 \\
\hline $\begin{array}{c}\text { Kyushu } \\
\text { EPCo }\end{array}$ & 0.996 & 0.976 & 0.971 & 0.952 & 0.950 & 0.967 & 0.988 & 0.889 & 0.926 & 0.960 & 0.979 & 0.994 & 1.019 & 0.987 & 0.968 \\
\hline $\begin{array}{l}\text { Tokyo } \\
\text { GasCo }\end{array}$ & 1.025 & 1.069 & 1.052 & 1.022 & 1.037 & 0.970 & 1.083 & 1.020 & 1.063 & 1.005 & 1.023 & 1.096 & 0.997 & 1.022 & 1.035 \\
\hline $\begin{array}{l}\text { Osaka } \\
\text { GasCo }\end{array}$ & 1.039 & 0.993 & 1.022 & 1.005 & 1.060 & 1.020 & 1.168 & 1.007 & 1.034 & 1.005 & 1.003 & 1.138 & 1.082 & 1.101 & 1.048 \\
\hline $\begin{array}{l}\text { Avg. } \\
\text { EPCo }\end{array}$ & 1.052 & 0.993 & 0.979 & 0.962 & 0.943 & 0.975 & 1.001 & 0.936 & 0.950 & 0.968 & 1.011 & 1.016 & 0.996 & 0.982 & 0.983 \\
\hline $\begin{array}{c}\text { Avg. } \\
\text { GasCo }\end{array}$ & 1.032 & 1.031 & 1.037 & 1.013 & 1.049 & 0.995 & 1.125 & 1.013 & 1.048 & 1.005 & 1.013 & 1.117 & 1.040 & 1.062 & 1.041 \\
\hline Total Avg. & 1.049 & 1.000 & 0.990 & 0.971 & 0.962 & 0.979 & 1.024 & 0.950 & 0.968 & 0.975 & 1.011 & 1.035 & 1.004 & 0.997 & 0.994 \\
\hline
\end{tabular}




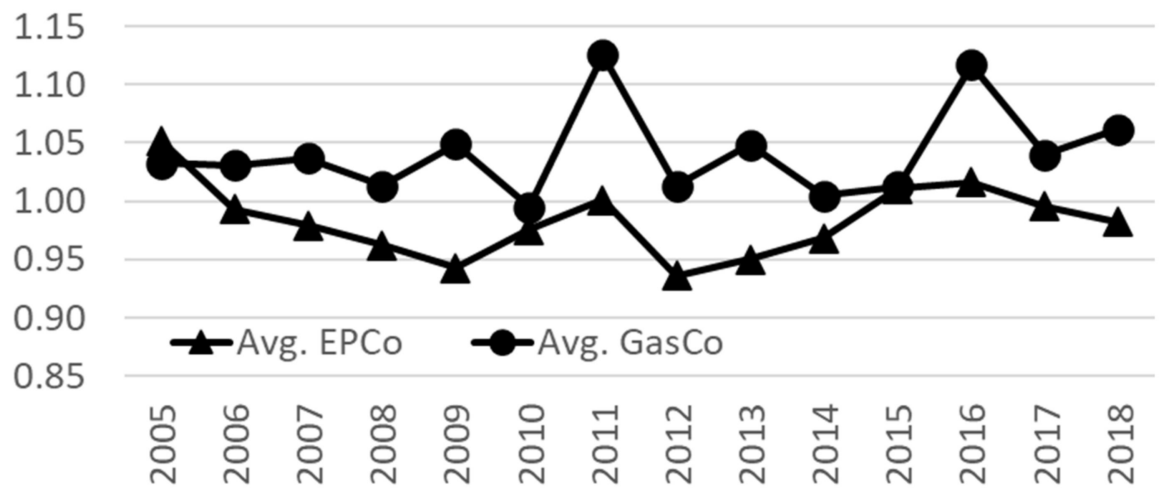

Figure 5. Operational Index (WOI) of Utility Companies: Index Measurement. Note: See the bottom of Tables 2-4.

This kind of difference is not found in the other efficiency measures $\left(C S O E_{k t}^{c}\right.$ and $W O E_{k t}^{c}$ ). This finding implies that the gas industry showed technological progress under the economic growth, but the electric power industry did not have such progress in their operations. After 2012, the electric power industry gradually recovered from the nuclear disaster, but it did not achieve enough $W O I_{k t+1}^{c}$ that was slightly over unity in 2015 and 2016.

Statistical Tests: To examine the null hypothesis (e.g., no difference between electricity and gas companies), we apply the Mann-Whitney $\mathrm{U}$ test to $C S O E_{k t}^{c}$. The $\mu$ score measured by Equation (8) equals -7.034 , which rejects the null hypothesis at the $1 \%$ significance level, concluding there was a difference between the two utility firms. We apply the KruskalWallis rank sum test to $C S O E_{k t}^{c}$ to examine the null hypothesis for multiple periods. The $H$ score measured by Equation (9) equals 85.980 with 16 degrees of freedom, which rejects the null hypothesis at the $1 \%$ significance level, implying a difference on performance of electricity and gas companies among the observed periods.

\section{Conclusions}

This study compared between Japanese electricity and gas companies in terms of their operational efficiencies and indexes from 2002 to 2018 using the three DEA approaches. We provided two findings from the results. First, compared with the gas industry, the electricity industry was negatively affected by the progress of market reforms and disaster of Fukushima Daiichi Nuclear Power Plant. The damage of the nuclear disaster caused major difficulties in the operations of electricity companies. Second, both industries have been gradually improving their performance measures in most recent years, but the gas industry has outperformed the electricity industry. This may be partly explained by a time lag of market liberalization between them; gas market reforms are slightly behind electricity reforms in Japan. Such a regulatory situation is unmanageable for corporate leaders, but it is shown that electricity companies have more room to increase efficiency. Furthermore, the Japanese government envisions industrial policy to promote mutual competition between electricity and gas companies to enter each other's market that may produce strong and efficient integrated energy companies through market liberalization. Such a government vision could be more beneficial for the electricity companies than city gas companies, because the former has scale benefits with larger capital than the latter.

Methodologically, this study developed the three new types of DEA approaches to evaluate corporate performances and intertemporal changes of efficiency that are brought about technology innovation of the two utility industries. We have computed CSOE, WOE, and WOI measures, which have served as efficiency and index measure assessments in a time horizon. These approaches have not been explored in the previous studies. We used the proposed approaches to avoid a "methodological bias", or limitation (i.e., different methods produce different results) often found in many empirical studies to guide large 
policy issues. In particular, DEA suffers from this type of problem, because it is for weight estimation (thus, nonparametric) among production factors. This difficulty requires that it is necessary for us to compare several methods and then to conclude policy suggestions on large issues such as energy and environment.

Academic Implications: The economic assertion believed by [9] assumes, "there are similarities between electricity and gas services in the utility industry so that they have a synergy effect between them." Previous studies [10,11] have empirically investigated the assertion by comparing electricity-specialized and diversified firms in the US, concluding that the two utility services do not have technological similarities at the level of receiving synergy effect between gas and electricity under US deregulation. Although this study does not directly examine synergy effects between electricity and city gas businesses, we have confirmed from the empirical results that there are significant differences in corporate performance between the two industries over the observed periods, thereby seeking the synergy effect under a new business model may be a significant business issue for corporate leaders in electricity companies with lower efficiency measures.

Policy Implication: Compared to the electricity companies, the gas companies had limited influence from competition because of the lagged schedule of market reforms in Japan. They were also not directly impacted by the nuclear disaster. In contrast, the electricity companies had a significant negative effect from the disaster. Consequently, gas companies outperformed electricity companies in all three measures in most observed periods. From the results, the government policy suggestion for integrated energy companies may be a more beneficial strategy for electricity companies than gas companies, because the former have greater business sizes with larger sales and capital assets. Moreover, it is generally expected that deregulation reduces utility service prices via market competition that increases benefits for consumers. Our empirical study did not directly examine the electricity and gas utility service prices. Rather, we were interested in more fundamental factors measured by operational efficiencies (CSOE and WOE) and technology innovation index (WOI) over time because improved $O E$ and $O I$ might lead to decreased prices through the improved corporate performance of the two utility industries. Thus, this study recommends that the Japanese government needs to examine the level of business competition by considering that the merger between electricity and gas services is most effective for utility companies in terms of their operational efficiency improvements and new technology innovations.

As an extension, this study leads to the consideration of two future research tasks. First, we should consider theoretical linkages between DEA approaches and statistical tests under multiple solutions (e.g., multiple projections, multiple reference sets, and multiple supporting hyperplanes). DEA usually suffers from an occurrence of such multiple solutions. Second, we must consider other applications on energy industries (e.g., petroleum and renewable energy [22-24]), whose assessments include environmental factors, such as polluted water and $\mathrm{CO}_{2}$ emissions, in their production processes.

In conclusion, it is hoped that we make a contribution in DEA applied to the energy utility industry. We look forward to seeing future extensions as discussed in this study.

Author Contributions: Conceptualization, T.S. and M.G.; methodology, T.S.; software, M.G.; validation, T.S. and M.G.; formal analysis, T.S. and M.G.; investigation, T.S. and M.G.; resources, M.G.; data curation, M.G.; writing—original draft preparation, T.S. and M.G.; writing—review and editing, T.S. and M.G.; visualization, T.S. and M.G.; supervision, T.S. and M.G.; project administration, M.G.; funding acquisition, M.G. All authors have read and agreed to the published version of the manuscript.

Funding: This research was funded by the Japan Society for the Promotion of Science (JSPS) Grantin-Aid for Scientific Research (KAKENHI) 19K04878, 20KK0106, and 20H00081.

Data Availability Statement: Financial data were obtained from S\&P Capital IQ and restrictions apply to the availability of these data. Patent data are available at WIPO IP Portal Patentscope ( https:/ /ipportal.wipo.int/, accessed on 18 March 2021).

Acknowledgments: We appreciate constructive comments from two anonymous reviewers that improved the quality of this paper. 
Conflicts of Interest: The authors declare no conflict of interest.

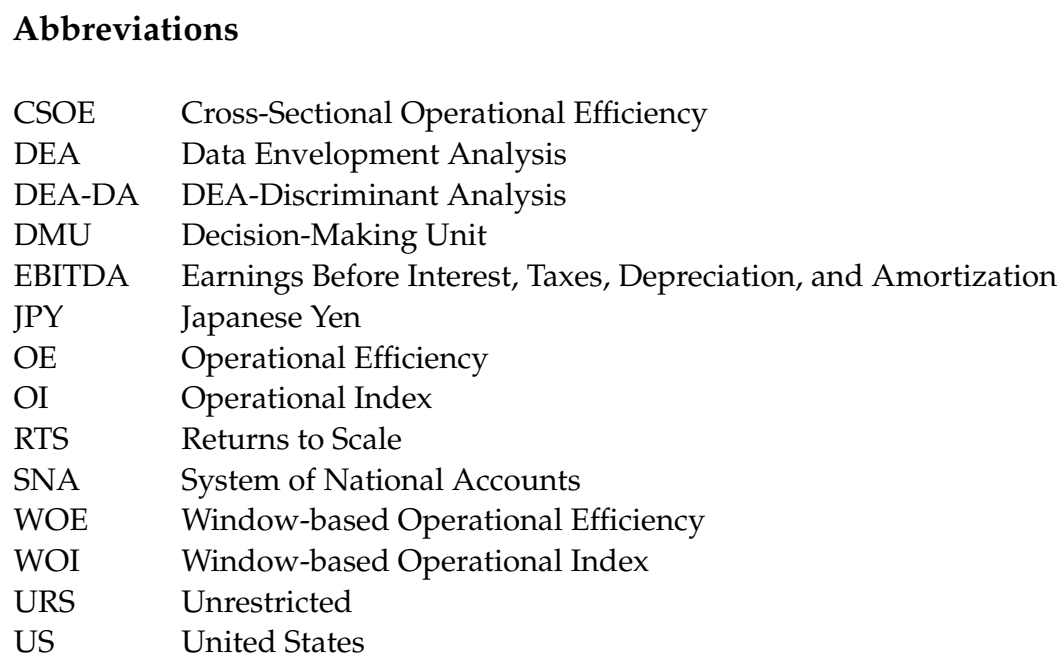

\begin{abstract}
Abbreviations
$X$ : a column vector of $m$ inputs and G: a column vector of $s$ outputs. $x_{i j t}$ is the observed $i$ th input of the $j$ th DMU $(i=1, \ldots, m \& j=1, \ldots, n)$ at the $t$ th period, $g_{r j t}$ is the observed $r$ th output of the $j$ th $\operatorname{DMU}(r=1, \ldots, s \& j=1, \ldots, n)$ at the $t$ th period, $\xi$ is an inefficiency score, $d_{i t}^{x}$ is an unknown slack variable of the $i$ th input at the $t$ th period, $d_{r t}^{g}$ is an unknown slack variable of the $r$ th output at the $t$ th period, $R_{i}^{x}$ is the data range on the $i$ th input, and $R_{r}^{g}$ is the data range on the $r$ th output. $\lambda_{j t}$ is an unknown intensity (or structural) variable of the $j$ th DMU at the $t$ th period, s.t. means subject to, and $\varepsilon_{S}$ is a prescribed very small number.
\end{abstract}

\title{
References
}

1. Newbery, D. Electricity liberalization in Britain and the evolution of market design. In Electricity Market Reform: An International Perspective; Sioshansi, F.P., Pfaffenberger, W., Eds.; Elsevier: Oxford, UK, 2006; pp. 109-143.

2. Green, R. Electricity deregulation in England and Wales. In Deregulation of Electric Utilities; Zaccour, G., Ed.; Springer: Boston, MA, USA, 2012; pp. 179-202.

3. Kishimoto, J.; Goto, M.; Inoue, K. Do acquisitions by electric utility companies create value? Evidence from deregulated markets. Energy Policy 2017, 105, 212-224. [CrossRef]

4. Dias, M.F.; Jorge, S.F. Mergers between natural gas suppliers and electricity generators: Should. European consumers be concerned? Energy Procedia 2016, 106, 185-203. [CrossRef]

5. Goto, M.; Sueyoshi, T. Electric power market reform in Japan after Fukushima: Issues and future direction. Int. J. Energy Sect. Manag. 2015, 9, 336-360. [CrossRef]

6. Agency for Natural Resources and Energy. Available online: https://www.enecho.meti.go.jp/category/electricity_and_gas/ energy_system_reform/ (accessed on 22 January 2021). (In Japanese).

7. Agency for Natural Resources and Energy (2015). Available online: https://www.enecho.meti.go.jp/committee/council/basic_ policy_subcommittee/018/pdf/018_006.pdf (accessed on 18 January 2021). (In Japanese).

8. Sueyoshi, T.; Yuan, Y.; Goto, M. A literature study for DEA applied to energy and environment. Energy Econ. 2017, 62, 104-124. [CrossRef]

9. Wilson, R. Architecture of power market. Econometrica 2002, 70, 1299-1340. [CrossRef]

10. Sueyoshi, T.; Goto, M.; Shang, J. Core business concentration VS. Corporate diversification in the US electric utility industry: Synergy and deregulation effects. Energy Policy 2009, 37, 4583-4594. [CrossRef]

11. Sueyoshi, T.; Goto, M. Operational synergy in the US electric utility industry under an influence of deregulation policy: A linkage to financial performance and corporate value. Energy Policy 2011, 39, 699-713. [CrossRef]

12. Cuadros, S.; Rodriguez, Y.E.; Contreras, J. Dynamic data envelopment analysis model involving undesirable outputs in the electricity power generation sector: The case of Latin America and the Caribbean countries. Energies 2020, 13, 6624. [CrossRef]

13. Liu, J.P.; Yang, Q.R.; He, L. Total-factor energy efficiency (TFEE) evaluation on thermal power industry with DEA, Malmquist and multiple regression techniques. Energies 2017, 10, 1039. [CrossRef]

14. Ziolo, M.; Jednak, S.; Savić, G.; Kragulj, D. Link between energy efficiency and sustainable economic and financial development in OECD Countries. Energies 2020, 13, 5898. [CrossRef] 
15. Akbar, U.; Khan, M.A.; Akmal, M.; Tóth Naárné, É.Z.; Oláh, J. Trade-offs for the optimal energy efficiency of road transportation: Domestic cases in developing countries. Energies 2020, 13, 6538. [CrossRef]

16. Xu, T.; You, J.; Li, H.; Shao, L. Energy efficiency evaluation based on data envelopment analysis: A literature review. Energies. 2020, 13, 3548. [CrossRef]

17. Mo, F.; Wang, D. Environmental sustainability of road transport in OECD countries. Energies 2019, 12, 3525. [CrossRef]

18. Nemoto, J.; Goto, M. Measurement of dynamic efficiency in production: An application of data envelopment analysis to Japanese electric utilities. J. Product. Anal. 2003, 19, 191-210. [CrossRef]

19. Nakano, M.; Managi, S. Regulatory reforms and productivity: An empirical analysis of the Japanese electricity industry. Energy Policy 2008, 36, 201-209. [CrossRef]

20. Sueyoshi, T.; Ryu, Y.; Goto, M. Operational performance of electric power firms: Comparison between Japan and South Korea by non-radial measures. Energies 2020, 13, 3968. [CrossRef]

21. Sueyoshi, T.; Goto, M. Environmental Assessment on Energy and Sustainability by Data Envelopment Analysis; John Wiley \& Sons: London, UK, 2018; pp. 1-699.

22. Sueyoshi, T.; Goto, M. Comparison among three groups of solar thermal power stations by data envelopment analysis. Energies 2019, 12, 2454. [CrossRef]

23. Sueyoshi, T.; Ryu, Y. Performance assessment of the semiconductor industry: Measured by DEA environmental assessment. Energies 2021, 13, 5998. [CrossRef]

24. Sueyoshi, T.; Ryu, Y.; Yun, J.-Y. Coronavirus-19 response and prospects of clean/sustainable energy transition in industrial nations: New environmental assessment. Energies 2021, 1174, 1-27. 